\title{
A recepção das premissas de Haeckel na obra de Jung ${ }^{\star}$
}

\author{
Victor de Freitas Henriques ${ }^{\text {Orcid, } \star \star}$ Walter Melo Junior ${ }^{\text {Orcid }}$ \\ Universidade Federal de São João del-Rei, São João del-Rei, MG, Brasil
}

\begin{abstract}
Resumo
Este artigo analisa a apropriação da teoria da recapitulação da filogênese pela ontogênese do biólogo Ernst Heinrich Philipp August Haeckel pelo psiquiatra suiço Carl Gustav Jung na formulação de seu projeto de psicologia, denominado Psicologia Analítica. Para isso, foram utilizadas definições contidas na obra Símbolos da Transformação, além do conceito de arquétipo, que estabelecem diálogos entre os campos da biologia e da psicologia. A formação biológica de Jung, aliada a seu interesse e prática no campo da psicologia, possibilitou uma ampliação em seu modo de conceber os fenômenos que observava. A tentativa de abordar um tema tanto pelo viés biológico quanto psicológico revela não só um cuidado como, também, o compromisso com a produção de conhecimento, que, mais do que buscar engrandecer seu campo original de trabalho, pretende estabelecer o diálogo interdisciplinar. Sendo o livro Símbolos da Transformação a obra através da qual Jung se prontifica a divulgar suas teorias e ideias próprias, podemos depreender que ao utilizar em tal trabalho certas premissas de Haeckel o autor acaba nos revelando uma de suas importantes influências epistemológicas.
\end{abstract}

Palavras-chave: filogênese; ontogênese; interdisciplinaridade; Jung; Haeckel.

\section{The reception of Haeckel's premises in Jung's work}

\begin{abstract}
This article analyzes the appropriation of the theory of recapitulation of phylogenesis by the ontogenisis, of the biologist Ernst Haeckel, by the Swiss psychiatrist Carl Gustav Jung in the formulation of his psychology project. For this purpose, we used the definitions contained in the book Symbols of Transformation, and the concept of archetype, that establish dialogues between the fields of biology and psychology. The biological formation of Jung, combined with his interest and practice in the field of psychology, allowed an amplification in his way of conceiving the phenomena he observed. The attempt to address a theme, both biologically and psychologically, reveals not only care but also a commitment to the production of knowledge, which, rather than seeking to enhance its original field of work, seeks to establish interdisciplinary dialogue. Being the book Symbols of Transformation, the work through which Jung is prepared to divulge his own theories and ideas, we can deduce that in using in such work certain premises of Haeckel the author ends up revealing to us one of his important epistemological influences.
\end{abstract}

Keywords: phylogenisis; ontogenisis; interdisciplinarity; Jung; Haeckel.

\section{Introdução}

Este artigo está inserido na linha de pesquisa Fundamentos, Método e Clínica da Psicologia Analítica, coordenado pelo Grupo Caminhos Junguianos (GCJ) da Universidade Federal de São João del-Rei (UFSJ), priorizando o debate interdisciplinar, através do diálogo de Jung com autores de diversas áreas do conhecimento, dentre os quais o biólogo Ernst Haeckel. Nesse sentido, podemos dizer que o projeto de psicologia desenvolvido por Carl Gustav Jung, designado como Psicologia Analítica, recebeu grande influência de seu conhecimento em biologia, adquirido através de sua formação médica. Em alguns conceitos utilizados pelo autor, como a ideia de arquétipo e de libido, assim como na concepção de seu consagrado teste de associação de palavras, podemos perceber o esforço de conciliação entre os pressupostos biológicos e as explicações fundadas em instâncias psíquicas.

Na autobiografia Memórias, Sonhos, Reflexões, Jung $(1961 / 1990)$ relata ter iniciado seus estudos em medicina na Universidade da Basiléia, na Suíça, em 1895, uma consequência de seus interesses pelas ciências naturais, que dividia espaço com seus estudos acerca de temas como religião e filosofia. Passado algum tempo de seu

\footnotetext{
^Fonte de Financiamento: Programa de Pós-Graduação em Psicologia da Universidade Federal de São João del-Rei.

$\star \star$ Endereço para correspondência: Universidade Federal de São João del-Rei. Campus Dom Bosco. Praça Dom Helvécio, 74, sala 1.53. São João del Rei, MG - Brasil.CEP: 36301160.E-mails: vf_henriques@hotmail.com,wmelojr@gmail.com
}

ingresso na universidade, Jung tornou-se assistente na disciplina de anatomia e encarregado do curso de histologia, ramo da biologia que estuda a função e estrutura dos tecidos vivos. Jung diz ter se interessado pela teoria da evolução ${ }^{1}$ e pela anatomia comparada.

Em 1899, na reta final de sua formação acadêmica, Jung ponderou a escolha pela especialização em cirurgia devido à inclinação para a anatomia, mas, devido a restrições financeiras, contentou-se com a possibilidade de trabalhar como clínico em um hospital. Ao se preparar para os exames finais, Jung entrou em contato com um manual de psiquiatria de Richard Von Krafft-Ebing, disciplina que não lhe despertava o menor interesse (JUNG, 1961/1990). De acordo com Pereira (2009), Krafft-Ebing foi o responsável por incorporar as noções de sadismo, masoquismo e fetichismo na literatura médica. O que impactou Jung, no entanto, foi a afirmação de que a psiquiatria lida com a personalidade. De acordo com Jung (1961/1990, p. 104): "num relance, como que através de uma iluminação, compreendi que não poderia ter outra meta a não ser a psiquiatria. Somente nela poderiam confluir os dois rios do meu interesse, cavando seu leito num único percurso".

\footnotetext{
A teoria da evolução não é um construto único, tendo sido alvo de inúmeras abordagens ao longo dos anos. A teoria de Charles Darwin é uma das mais conhecidas e foi amplamente difundida para o público de língua alemã, segundo Winograd e foi amplamente difundida para o público de lingua alemã, segundo Winograd
(2007), através das traduções realizadas pelo biólogo Ernst Haeckel. A edição de A Origem das Espécies, de Charles Darwin, publicada pela editora portuguesa Planeta Vivo, em 2009, possui uma secão denominada Resenha histórica, na qual realiza um levantamento das principais ideias acerca do tema evolução e origem das espécies à época que antecede a publicação de Darwin sobre o tema.
} 
Jung nos conta que o estudo de medicina fez com que se dedicasse menos aos temas filosóficos, que lhe eram tão caros, restringindo-se a algumas leituras nos finais de semana. A possibilidade de retomada desse foco de interesse, aliada a sua prática médica, fez com que a psiquiatria parecesse uma escolha viável. Sobre isso, diz: "lá estava o campo comum da experiência dos dados biológicos e dos dados espirituais, que até então eu buscara inutilmente. Tratava-se, enfim, do lugar em que o encontro da natureza e do espírito se torna realidade" (JUNG, 1961/1990, p. 104).

De acordo com Sonu Shamdasani (2003/2005), Jung concluiu a faculdade de medicina em 1900, tornando-se médico-assistente de psiquiatra do Hospital Burghölzli, em Zurique. De início, a maior parte do trabalho de Jung consistia na dissecação e análise de cérebros no intuito de descobrir, através da anatomia, alguma causa para os transtornos mentais. Essa atividade teria se revelado pouco produtiva, fazendo com que o interesse de Jung pela anatomia cerebral fosse se esvaindo. A grande contribuição de Jung para a psiquiatria em seus tempos de médico-assistente se deu através dos testes de associação de palavras, como "instrumento que ajudasse no diagnóstico diferencial dos distúrbios mentais" (SHAMDASANI, 2003/2005, p. 60). A hipótese de Jung (1907/2013a) era a de que determinadas respostas eram frutos de perturbações do campo da consciência, advindas de associações afetivas estruturadas para além do campo da consciência. Jung denominou como complexo de tonalidade afetiva a estrutura responsável por tais perturbações. Os testes de associação renderam amplo reconhecimento a Jung.

$\mathrm{O}$ interesse de Jung em relação aos aspectos inconscientes levou-o ao encontro do círculo psicanalítico de Viena, com o qual romperia anos mais tarde, devido a divergências político-conceituais. Foi através do livro $A$ Interpretação dos Sonhos que o psiquiatra suíço conheceu o pensamento de Sigmund Freud. A noção de inconsciente possibilitou a Jung lançar um novo olhar sobre a relação entre a base orgânica e os conteúdos psíquicos para além da formação estritamente médica.

Este artigo analisa a apropriação da teoria da recapitulação da filogênese pela ontogênese do biólogo Ernst Haeckel pelo psiquiatra suíço Carl Gustav Jung na formulação de seu projeto de psicologia. Para isso, foram utilizadas definições contidas na obra Símbolos da Transformação (JUNG, 1952/2013c), além do conceito de arquétipo, que estabelecem diálogos entre os campos da biologia e da psicologia.

\section{A teoria de Haeckel}

Ernst Heinrich Philipp August Haeckel foi um biólogo alemão responsável pela divulgação da lei biogenética, a teoria de que a ontogênese recapitula a filogênese que, em linhas gerais, diz que cada indivíduo de determinada espécie traz consigo a herança da forma e do comportamento de seus antecessores, transmitida geração após geração. A lei de Haeckel é postulada em 1874 em seu livro Anthropogenie oder Entwickelungsgeschichte des Menschen, ${ }^{2}$ no qual diz

${ }^{2}$ Antropogenia ou a história evolutiva do homem (tradução livre). que o feto, em seu amadurecimento, passaria por todas as etapas evolutivas referentes ao desenvolvimento de sua espécie. Essas etapas seriam preservadas através de caracteres hereditários, possuindo funções adaptativas. Haeckel teria sido "um apóstolo do darwinismo", afirmado que "a teoria de Darwin era a chave para uma visão monista unificada do cosmos" (SHAMDASANI, 2003/2005, p. 204).

Haeckel criou o sistema filosófico conhecido como monismo, através do qual professava a unicidade da matéria, aplicando o modelo evolutivo de Darwin na compreensão do universo. Para o biólogo, as matérias orgânicas e inorgânicas não se diferenciavam, sendo que toda vida teria se originado da matéria não orgânica a partir da intervenção de uma entidade a qual chamou de monera (ELLENBERGER, 1970/1994). A afirmação de Haeckel de que teria visualizado a monera, com auxílio de um microscópio, não teria sido bem recebida em seu meio. O pensamento de Haeckel avançou para a ideia da existência de consciência em nível molecular, afirmação que, segundo Ellenberger (1970/1994), gozara de imenso prestígio à sua época, especialmente na Alemanha, sendo considerado um dos pilares na construção da chamada psiquiatria dinâmica moderna.

As ideias de Haeckel teriam cruzado não só o campo da biologia como o próprio Atlântico, sendo recebidas pelo norte-americano Stanley Hall, criador da noção de "inconsciente filogenético" (SHAMDASANI, 2003/2005, p. 208). A lei da biogenética, transferida para o campo da psicologia, encontrou terreno no estudo do desenvolvimento humano a partir de profusão de estudos envolvendo crianças. A ideia de um substrato comum de caráter hereditário também foi algo concebido por Jung em seu trabalho, o que o levou a postular as noções de arquétipo e de inconsciente coletivo.

\section{O pensamento de Haeckel em Símbolos da Transformação, de Jung}

Em uma carta datada de 11 de dezembro de 1911, direcionada a Sigmund Freud, Jung comenta que a análise realizada pelo criador da psicanálise a respeito de Daniel Schreber, um juiz alemão cujo caso de adoecimento psíquico fora estudado por ambos, havia suscitado algumas dúvidas sobre a aplicação da teoria da libido. Jung observara o caso Schreber pela ótica da esquizofrenia (demência precoce), distúrbio que investigara em sua parceria com o psiquiatra Eugen Bleuler, enquanto Freud visualizara na história relatada por Schreber, em seu diário, a comprovação de sua teoria da sexualidade, gerando certo incômodo em Jung (BAIR, 2003/2006). A esse respeito, observa Jung:

A perda da função de realidade na D. pr. [demência precoce] não pode ser reduzida à repressão da libido (definida como desejo sexual). Não por mim, de qualquer forma. A sua dúvida demonstra-me que, também ao seu ver, o problema não pode ser resolvido dessa maneira. Juntei agora todas as ideias sobre o conceito de libido que me ocorreram ao longo dos anos e dediquei a elas um capítulo na segunda parte do trabalho. [...] O ponto essencial é que tento substituir o conceito descritivo por um conceito genético da libido. Tal 
conceito abrange não apenas a libido sexual recente, mas todas aquelas formas de libido que há muito se dividiram em atividades organizadas. Um pouquinho de biologia era inevitável aqui (McGUIRE, 1976, p. 537, grifo do autor).

Nessa carta, Jung se refere ao livro Símbolos da Transformação, o qual se encontrava em processo de formulação. Ao analisar a relação de Jung e Freud nesse período, Bair (2003/2006) chama a atenção para o conflito que a proposta de expansão do conceito de libido, por parte de Jung, gerara entre os dois pensadores. Em uma nota de rodapé, a biógrafa diz que, ao buscar um conceito genético para embasar sua proposta de libido, utilizando-se da biologia, Jung estaria se pautando nas premissas de Haeckel acerca da recapitulação da filogenia pela ontogenia. A biógrafa diz, ainda, que Jung "usou algumas das ideias de Haeckel em Wandlungen [Símbolos da Transformação], mas não o citou especificamente" (BAIR, 2003/2006, p. 540).

No capítulo dedicado ao conceito de libido, Jung (1952/2013c, p. 165) a define como energia psíquica que "filogeneticamente são as necessidades físicas como fome, sede, sono, sexualidade, e os estados emocionais, os afetos". Jung (1952/2013c, p. 166) segue sua descrição dizendo que os fatores que compõem a energia psíquica tiveram sua origem em "formas primitivas mais simples [que sofreram deslocamentos na] série ascendente dos animais". Nessas passagens, podemos perceber uma clara apropriação do pensamento biológico evolutivo de Haeckel por Jung.

Além da formulação de seu conceito de libido, Jung aborda o tema da existência de dois tipos de pensamento: o pensamento dirigido e o pensamento fantasia. O pensamento dirigido é voltado para a assimilação da realidade de modo objetivo, ordenando os fatos por meio de sucessões causais com auxílio da linguagem. O pensamento fantasia é expresso através dos sonhos e outras formas de imagens criadas espontaneamente pelo inconsciente. Na primeira edição de Símbolos da Transformação o pensamento dirigido é descrito como estando voltado para a adaptação, enquanto o pensamento fantasia não cumpriria esta função. Na quarta edição, porém, Jung acrescenta uma nota de rodapé dizendo que o pensamento fantasia também cumpriria esta função, pois no inconsciente também haveria "forças e conteúdos criativos" (JUNG, 1952/2013c, p. 39).

A concepção de dois tipos de pensamento também aproxima Jung da teoria biogenética de Haeckel. O pensamento fantasia é visto por Jung como uma faculdade fundamental do homem primitivo. Ao postular a existência de um substrato comum em nosso psiquismo, no qual herdamos a potencialidade do comportamento e das expressões humanas, o pensamento fantasia seria uma função que nos fora repassada, ora concorrendo ora complementando o pensamento dirigido, adquirido com o passar do tempo. O interesse de Jung pelos povos primitivos reside na ideia de podermos averiguar, a partir da compreensão dos elementos que rodeiam suas ações, a estrutura de nossa psique. Os estudos acerca da mitologia e do folclore surgiriam como uma busca pela compreen-

Fractal, Rev. Psicol., v. 31 - n. 1, p. 11-15, 2019 são da linguagem, na qual esse tipo de pensamento se manifestaria: os símbolos. Em carta datada de novembro de 1909, Jung diz a Freud:

Um dos motivos que me levaram a deixar de escrever por tanto tempo foi que passei as minhas noites imerso na história dos símbolos, i.e., na mitologia e na arqueologia. Andei lendo Heródoto, onde achei coisas maravilhosas (p. ex., Livro II, culto de Papremis). Agora estou lendo os 4 volumes do velho Creuzer, nos quais há uma mina de material. Todo meu interesse pela arqueologia (latente há anos) voltou de novo a se manifestar. Aqui se encontram fontes valiosas para a fundamentação filogenética da teoria da neurose (McGUIRE, 1976, p. 310).

Em outra carta, também para Freud, datada de dezembro de 1909, Jung segue comentando sobre a importância dos estudos mitológicos na compreensão filogenética da psique:

Tornou-se-me absolutamente claro que não desvendaremos os segredos finais da neurose e da psicose sem a mitologia e a história da civilização, pois a embriologia vai de par com a anatomia comparada e sem a última a primeira não passa de uma contrafação da natureza que permanece incompreendida no âmago (McGUIRE, 1976, p. 333).

Dessa maneira, mais do que propor um método de compreensão dos conteúdos inconscientes do psiquismo, Jung estava iniciando a formulação de uma fenomenologia da psique, buscando nos próprios conteúdos manifestos a razão de ser dessa camada coletiva.

\section{A noção de arquétipo na obra de Jung}

As concepções de arquétipo e de inconsciente coletivo são indissociáveis. Sobre o inconsciente coletivo, Jung (1936/2012d) diz se tratar de uma matriz psicológica comum a todo ser humano, não sendo pessoal, mas herdada e de cunho universal. Os conteúdos do inconsciente coletivo são os arquétipos, estruturas inatas de percepção e apreensão do mundo. A construção dos conceitos de arquétipo e de inconsciente coletivo por Jung remonta, segundo Shamdasani (2003/2005), à proposta de investigação a que o psiquiatra suíço estava se dedicando por volta de 1909: a tentativa de estabelecer as bases filogenéticas da teoria das neuroses. Assim como os estudos de filogenia, embriologia e anatomia comparada constituíam o conjunto a partir do qual seria possível, para a biologia, investigar as origens do comportamento humano, Jung estaria procurando, envolto pelo pensamento biologicista de sua época, um meio pelo qual fosse possível compreender o psiquismo e seus conteúdos, pautando-se na ideia da existência de estruturas psíquicas que foram sendo desenvolvidas e, posteriormente, transmitidas.

Um dos principais motivos que teria levado Jung a propor tal raciocínio fora o surgimento de conteúdos mitológicos, não pessoais, na fala de um paciente que discursava sobre a presença de um falo que pendia do sol, origem do vento. Alguns anos após esse relato, Jung se deparou com um manuscrito mitológico que versava sobre o mesmo tema: a origem do vento a partir do sol. O manuscrito havia sido descoberto e traduzido posteriormente, o que implicaria admitir que o paciente de Jung não possuía conhecimento consciente sobre o tema. Des- 
sa maneira, Jung (1952/2013c) postulou que parte dos conteúdos de nossa psique tinha como base estratos em comum com a história da humanidade, que se expressavam em uma linguagem própria: simbólica e mitológica.

Em 1936, Jung ministrou uma palestra na Sociedade Abernethiana, no Hospital de São Bartolomeu, em Londres, posteriormente publicada com o título de $O$ conceito de inconsciente coletivo, para esclarecer esta noção. Nessa conferência, Jung (1936/2012d, p. 53) diz que os instintos são "forças motrizes especificamente formadas, que perseguem suas metas inerentes antes de toda conscientização, independendo do grau de consciência". Partindo desse postulado inicial, Jung sugere que os arquétipos seriam expressões imagéticas dos instintos. Ressalta, ainda, que os arquétipos não trazem consigo um conteúdo dado, sendo, antes de tudo, "formas sem conteúdo" (JUNG, 1936/2012d, p. 57), possibilidades de percepção e de ação. A ideia do arquétipo como expressão do instinto aproxima Jung da noção biogenética de Haeckel, pois diz de uma estrutura herdada comum a toda espécie que possui função adaptativa.

Algumas passagens da obra de Jung evidenciam aproximações com a proposta de Haeckel. Em artigo intitulado "Aspectos gerais da psicologia do sonho", Jung (1928/2013b, p. 197) diz que “o pensamento onírico é uma forma filogenética anterior de nosso pensamento [e que] nosso organismo conserva os traços de sua evolução filogenética, [sendo que] o mesmo se dá com o espírito humano, [e] nada há de espantar quanto à possibilidade de que a linguagem figurada dos sonhos seja um vestígio arcaico de nosso pensamento". Outra afinidade com o pensamento de Haeckel aparece no livro A energia psíquica, no qual Jung (1928/2012a, p. 65-67, grifo do autor) diz:

Da disposição embrionária infantil surgirá posteriormente o ser humano inteiro, razão pela qual a disposição embrionária não é pura sexualidade, da mesma maneira que a psique do ser humano adulto não o é. Além disso, essa disposição embrionária não contém unicamente o começo de uma vida adulta, mas também toda a herança da série de antepassados, de extensão indefinida. Essa herança ancestral compreende não só os instintos provenientes, lá atrás, do estágio animal, mas também todas as diferenciações que legaram traços hereditários.

Costuma-se encarar com ceticismo esse tipo de hipótese porque acreditam tratar-se de "ideias herdadas". É obvio que nem sequer podemos pensar nisso. Trata-se antes de possibilidades de pensamentos herdados, de "trilhas", que foram formando com o acúmulo gradual das experiências dos ancestrais.

Negar a constituição hereditária dessas trilhas seria o mesmo que negar a constituição hereditária do cérebro. Para serem coerentes, tais pessoas deveriam defender a tese de que a criança nasce com um cérebro de macaco. Mas como ela nasce com um cérebro humano, esse cérebro mais cedo ou mais tarde vai começar a funcionar como humano, e vai começar necessariamente no nível dos mais recentes antepassados.

Outra passagem da obra de Jung que evidencia a aproximação de seu pensamento com a teoria da recapitulação da filogênese pela ontogênese pode ser encontra- da na segunda das cinco conferências que apresentou em Londres no ano de 1935, que ficaram conhecidas como as conferências de Tavistock. Ao falar sobre análise de sonhos, Jung (1935/2012c, p. 56) diz:

Nossa mente tem sua história, bem como nosso corpo. Pode-se às vezes ficar intrigado pelo fato de o homem ter um apêndice. Para que serve? Bem, ele nasceu assim, e acabou-se. Milhões de pessoas não sabem que têm um timo, mas isso não impede que ele exista. Também não sabem que, em certa parte, sua anatomia pertence à espécie dos peixes, entretanto é assim. Nossa mente inconsciente, bem como nosso corpo, é um depositário de relíquias e memórias do passado. Um estudo da estrutura do inconsciente coletivo revelaria as mesmas descobertas que se fazem em anatomia comparada.

Em uma conferência realizada na Sociedade de Filosofia Livre, em 1937, na Alemanha, Jung (1937/2012e, p. 41) apresentou o artigo "Alma e terra", no qual diz:

De acordo com a lei filogenética, recapitulamos, em nossa infância, reminiscências da pré-história da raça e da humanidade em geral. Filogeneticamente, procedemos e evoluímos dos obscuros confins da terra. Por isso os fatores que mais nos afetaram se transformaram em arquétipos e são estas imagens primordiais que nos influenciam mais diretamente e por isso também parecem ser as mais poderosas.

Embora no artigo "Sobre os arquétipos do inconsciente coletivo", Jung (1934/2012b, p. 13) enuncie ter retirado o termo arquétipo de pensadores como os filósofos clássicos Platão e Filo Judeu, assim como de Santo Agostinho e do bispo Irineu de Lyon, que utilizavam o termo para tratar de "tipos arcaicos - ou melhor - primordiais, isto é, de imagens universais que existiram desde os tempos mais remotos", não podemos deixar de considerar que a teoria dos arquétipos parece ter se beneficiado dos postulados biogenéticos de Haeckel. A ideia do surgimento de estruturas de apreensão da realidade, que se fazem presente em todo indivíduo da espécie humana, contendo vestígios de modos de atuação e atualizando a experiência humana com base na linguagem simbólica, coaduna-se perfeitamente com as disposições da lei biogenética.

Ambas as propostas, a da existência de arquétipos e a da recapitulação da filogênese pela ontogênese, sofreram retaliações. Shamdasani (2003/2005) afirma que Jung fora acusado de operar conceitos de teor lamarckista e de propor a tese da possibilidade de transmissão de ideias por meio de processos hereditários. Apesar de Jung ressaltar que os arquétipos não representam conteúdos, mas apenas a forma para que o conteúdo possa ser apreendido, tal alegação se manteve entre os críticos de suas proposições.

O mesmo acontece com Haeckel. Richards (2009) nos conta que ainda hoje há a tentativa de desmerecimento da teoria de Haeckel, pautando-se em uma possível fraude em seus experimentos com embriões, nos quais teria omitido algumas estruturas anatômicas a fim de proteger suas alegações. Contudo, a lei biogenética possuiria tanto adeptos quanto desafetos, revelando diferentes correntes do estudo em embriologia.

Fractal, Rev. Psicol., v. 31 - n. 1, p. 11-15, 2019 
O pensamento de Haeckel ecoa nas proposições de Jung até meados da década de trinta, mas podemos assegurar que se restringe à qualidade de ilustração dos postulados do psiquiatra suíço. Xavier (2012, p. 151) diz que, apesar de não abrir "mão de seu porto seguro em uma concepção de natureza unificada", Jung não pode ser considerado nem monista nem dualista, pois "mantinha-se atento às diversas antinomias" existentes na psique. Xavier sugere a ideia de complementariedade, cunhada pelo físico Niels Bohr, para compreendermos os postulados de Jung, no qual monismo e dualismo parecem conversar. Desse modo, podemos pensar que a recepção das teorias de Haeckel na obra de Jung constitui-se como um evento circunscrito, uma parcela ilustrativa que ganhou importância em determinados momentos da obra de Jung.

A formação biológica de Jung, aliada a seu interesse e prática no campo da psicologia, possibilitou uma ampliação em seu modo de conceber os fenômenos que observava. A tentativa de abordar um tema tanto pelo viés biológico quanto psicológico revela não só um cuidado como o compromisso com a produção de conhecimento, que, mais do que buscar engrandecer seu campo original de trabalho, pretende estabelecer o diálogo interdisciplinar.

\section{Referências}

BAIR, Deirdre. Jung, uma biografia (2003). São Paulo: Globo, 2006. v. 2.

ELLENBERGER, Henri F. The discovery of the unconscious: the history and evolution of dynamic psychiatry (1970). London: Fontana, 1994.

HAECKEL,Ernst.AnthropogenieoderEntwickelungsgeschichte des Menschen. Leipzig: Engelmann, 1874.

JUNG, Carl Gustav. Memórias, sonhos, reflexões (1961). Rio de Janeiro: Nova Fronteira, 1990.

JUNG, Carl Gustav. A energia psíquica (1928). Petrópolis, RJ: Vozes, 2012a.

JUNG, Carl Gustav. Sobre os arquétipos e o inconsciente coletivo (1934). In: Os arquétipos e o inconsciente coletivo. Petrópolis, RJ: Vozes, 2012b. p. 11-50.

JUNG, Carl Gustav. Fundamentos de Psicologia Analítica (1935). In: _. A vida simbólica. Petrópolis, RJ: Vozes, 2012c. v. 18/1, p. 13-200.

JUNG, Carl Gustav. O conceito de inconsciente coletivo (1936). In: . Os arquétipos e o inconsciente coletivo. Petrópolis, RJ: Vozes, 2012d. p. 51-62.

JUNG. Carl Gustav. Alma e terra (1937). In: em transição. Petrópolis, RJ: Vozes, 2012e. p. 38-59.

JUNG, Carl Gustav. O complexo de tonalidade afetiva e seus efeitos gerais sobre a psique (1907). In: __. Psicogênese das doenças mentais. Petrópolis, RJ: Vozes, 2013a. p. 48-62.

JUNG, Carl Gustav. Aspectos gerais da psicologia do sonho (1928). In: Vozes, 2013b. p. 186-234.

JUNG, Carl Gustav. Símbolos da transformação (1952). Petrópolis, RJ: Vozes, 2013c.

McGUIRE, William. Freud e Jung: correspondência completa. Rio de Janeiro: Imago, 1976.

Fractal, Rev. Psicol., v. 31 - n. 1, p. 11-15, 2019
PEREIRA, Mário Eduardo Costa. Krafft-Ebing, a Psychopathia Sexualis e a criação da noção médica de sadismo. Rev. latinoam. psicopatol. fundam., São Paulo, v. 12, n. 2, p. 379-386, 2009. Cross $^{\text {Ref }}$

RICHARDS, Robert J. Haeckel's embryos: fraud not proven. Biol. Philos, n. 24, p. 147-154, 2009. Disponível em: http:/ home.uchicago.edu/ rjr6/articles/Haeckel--fraud $\% 20$ not $\% 20$ proven.pdf. Acesso em: 7 nov. 2015

SHAMDASANI, Sonu. Jung e a construção da psicologia moderna: o sonho de uma ciência (2003). Aparecida: Idéias \& Letras, 2005.

WINOGRAD, Monah. Freud e a filogenia anímica. Revista do Departamento de Psicologia - UFF, Niterói, v. 19, n. 1, p. 6981, 2007. Cross ${ }^{\mathrm{Ref}}$

XAVIER, Cesar Rey. A Psicologia e o problema mente-corpo: uma nova proposta para a imponderável epistemologia da consciência. Curitiba: Juruá, 2012.

Recebido em: 23 de novembro de 2015 Aceito em: 8 de novembro de 2018 